\title{
REACTIVITY OF INTACT BLOOD VESSELS OF THE FINGERS AND TOES TO SENSORY STIMULI IN NORMAL RESTING ADULTS, IN PATIENTS WITH HYPERTENSION, AND IN SENILE SUBJECTS ${ }^{1}$
}

\author{
By G. E. BURCH, 2 A. E. COHN, AND C. NEUMANN \\ (From the Hospital of the Rockefeller Institute for Medical Research, New York)
}

(Received for publication February 6, 1942)

That small blood vessels may react by constriction is well recognized. It is probable, in addition to smooth muscle, that there are other contractile elements. The sympathetic nervous system is generally regarded as playing a prominent role in their function. In certain states of disease and stress, the effect of this control is manifest in blanching, cyanosis, and coldness, or the reverse of these. Previous studies ( 1 to 3 ) have shown that small blood vessels undergo a continuous series of changes in size even in the resting subject. It is the object of this paper to describe the effect of applying sudden stimuli which disturb this resting state.

Although it would be possible, using figures for the chronaxie of the blood vessels in isolated strips of animal tissue (4 to 6), to estimate that of human blood vessels, this information, however valuable, is not necessarily applicable to the situation in intact human subjects. It became desirable, therefore, to adapt an older method, capable of yielding information which could be used to characterize the responses in man. Fano (quoted by Luciani (7)), many years ago, described the details of a method which made possible the measurement of changes in size of anatomical parts when various stimuli were applied at remote points. But Fano's apparatus was not sensitive to small changes. His results were disturbed, furthermore, by the inclusion of large arteries and veins in his plethysmographic chambers. In the present studies, the small blood vessels are of prime interest, making it desirable to choose the tips of fingers and toes. But even these parts contain arterioles, venules, capillaries, and arteriovenous communications, so that any result must be interpreted as representing the combined effect

1 This is the 9th paper reporting the results of studies of the small blood vessels and related subjects.

2 Commonwealth Fund Fellow. of the activity of many structures. In addition, it must be remembered that the pathway from the point of reception of a stimulus to the blood vessels involves many interconnecting structures, including the receptors, sensory nerves, synapses, the pathways within the central and autonomic nervous system, and neuromuscular junctions. Measurements in intact subjects give information concerning the time taken by the blood vessels to react only when the time required to traverse these complex pathways is taken into account. In point of fact, it is only in the post-ganglionic fibers of the sympathetic system that an interval of importance relative to the time of reaction of blood vessels is to be expected.

It is unknown what role the reactivity of small blood vessels to sensory stimulation plays in arterial hypertension. The cold pressor test (8) was developed to distinguish between individuals whose blood vessels are unusually reactive and who are potentially hypertensive and those whose blood vessels react in a normal fashion. An effort has now been made to characterize further the blood vessels of hypertensive individuals by obtaining data, not only on the degree of reaction, but also covering the time of reaction. For contrast, a group of senile subjects has been studied.

\section{METHOD}

The apparatus employed in these observations was essentially that previously described (3). It was modified for special purposes, as will be described later. It records simultaneously the changes in volume of the tips of the right index finger and the right second toe with a sensitive pneumoplethysmograph (9). The subjects rested in bed in an air-conditioned room (temperature $75^{\circ} \mathrm{F} . \pm 1^{\circ}$; relative humidity less than 50 per cent) at least 30 minutes before recording was started. In an early period of this study, the subjects rested in a room containing the apparatus as well as other laboratory equipment. Later, because of psychic disturbances produced by this unfamiliar environment, the examining room was redec- 


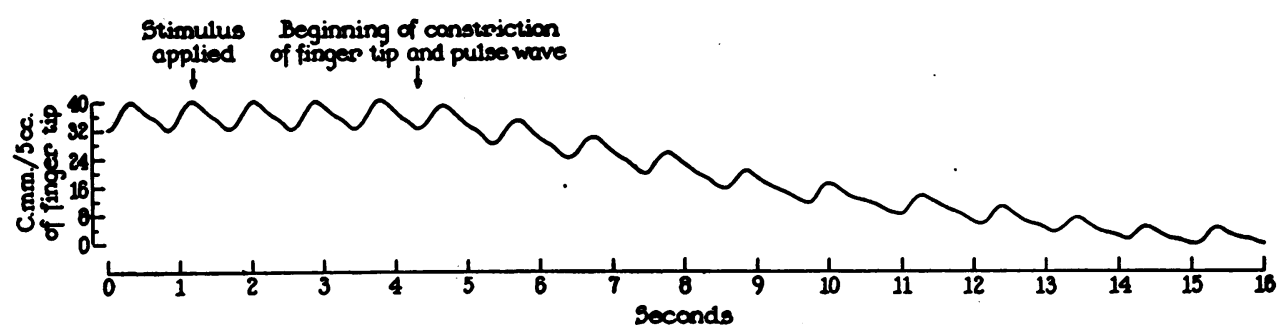

\section{Fig. 1. A Schematic Drawing Showing the Average Type of Reaction in the Finger Tips of All Subjects}

The units of time and volume and the rate of vasoconstriction are the mean values obtained.

orated to resemble a bedroom (10). Its walls were made sound proof. After plethysmographic cups were sealed in place, the tips of the fingers and toes were adjusted to the level of the subject's heart. The physician then departed. Evidence that subjects were "relaxed" appeared in the increase in volume of the pulse and alpha waves (3).

Once a subject reached a state of maximum relaxation, stimuli were applied and the reactions of the blood vessels, evidenced by changes in volume, were recorded. When stimuli were applied in order to measure the reaction time, the speed of the photographic paper was about 4 to $6 \mathrm{~cm}$. per second. Between stimuli, the paper ran at a rate of $8 \mathrm{~cm}$. per minute. The time of application of each form of stimulus was registered on the photographic record by a light beam, activated by a magnet. In each case, the act of applying the stimulus closed a circuit of which the magnet was a part.

The stimuli employed were light, sound, heat, cold, pinprick, and electric shock. Light, as a stimulus, was supplied for one second by a 500-watt photoflood lamp. Sound was made by ringing a telephone bell, 0.4 second, 3 feet from the subject. A sudden loud sound was produced by firing a cap-pistol about 3 feet away. Heat and cold were applied by touching the subject's arm on the external surface just above the left elbow with a metal plate $\left(11 \mathrm{sq} . \mathrm{cm}\right.$. in area) at $50^{\circ} \mathrm{C}$. and $3^{\circ} \mathrm{C}$. respectively. Pain was produced by a pin-prick of uniform force on the external surface of the arm, just above the left elbow. Electric stimulation was supplied by discharging a condensor (4.5 microfarads) at the same point. Contact between the electrodes and the subject's skin was made with a sodium chloride jelly, the resistance being adjusted to about 5000 ohms.

Subjects were not warned that they were to be tested for their reaction to certain stimuli. In the case of light and the bell, they were left alone. In the use of other stimuli, to avoid complicated apparatus, it was necessary that an observer enter the room. He erected a curtain between the subject and himself. The subjects did not know the order in which stimuli would be selected nor the time of their application.

Subjects were regarded as being relaxed when, after a reasonable period, their pulse and alpha waves had attained maximum proportions. Response to stimuli was documented by decrease in size of these waves. Re- covery was known to have taken place on return of the waves to their original volumes.

The reaction time to a stimulus was the time taken for a change in volume to begin (Figure 1). To study changes in volume, only the finger tips were measured. The measurements made were: (1) the initial volume of the pulse wave, (2) the volume of the pulse wave at its minimum, (3) the maximum change in "alpha" waves," (4) the time required for the "alpha" wave to reach a minimum, (5) the time required for the "alpha" wave to return to the original volume, and (6) the phase of the "alpha" wave when the stimulus was applied.

The reaction was identified as beginning at the intersection of a line joining the foot points of the last few pulse waves before the onset of vasoconstriction (decrease in size of the waves), with another joining those just afterward. The study of a pulsating model suggested that this point was located with an error no greater than 0.05 second.

The subjects chosen for investigation included 17 normal individuals (12 males and 5 females), varying in age from 11 to 43 years, 12 hypertensive patients (6 males and 6 females), varying in age from 14 to 54 years, and 11 male senile subjects, varying in age from 70 to 85 years. All of the subjects were free from renal or cardiac failure. Each subject was studied at least twice and some as often as 12 times.

\section{RESULTS}

The mean time of reaction of the finger tips of the normal subjects in 178 responses was $3.12 \pm$ 0.02 seconds, with a standard deviation of $0.33 \pm$ 0.01 second and a coefficient of variation ot $10.6 \pm 0.04$ per cent, and that of the toes in only 63 responses of many trials, $3.42 \pm 0.04$ seconds with a standard deviation of $0.49 \pm 0.03$ second and a coefficient of variation of $14.4 \pm 0.9$ per cent. The means of the two (fingers and toes) were significantly different (3.12 as against 3.42 seconds). Although the toe usually reacted after

8 The reason for the use of quotation marks about the alpha will be explained later. 
the finger, in rare instances the order was reversed. The mean reaction times for each stimulus in the finger tip were: bell, 3.33 seconds; light, 3.26 ; sound, 3.07 ; cold, 3.07 ; heat, 3.04 ; pinprick, 2.95 ; and shock 2.86 (Table I).

The mean time of reaction of the vessels of the tips of the right index finger of patients with hypertension, in 159 responses, was $2.94 \pm 0.03 \mathrm{sec}-$ onds, with a standard deviation of $0.50 \pm 0.02$ second and a coefficient of variation of $17.0 \pm 0.7$ per cent; and of the tips of the right second toe, in 56 responses, the mean reaction time was $3.24 \pm 0.04$ seconds, with a standard deviation of $0.50 \pm 0.03$ second and a coefficient of variation of $15.4 \pm 1.1$ per cent (Table II). The means of the reaction times of the fingers and toes differed by 0.30 second. This was found to be statistically significant. The mean reaction times for each stimulus in the finger tips were: light, 3.39 ; sound, 3.00 ; bell, 2.92 ; heat, 2.91 ; cold, 2.89 ; and pinprick, 2.81 seconds. These mean values cannot be considered significantly different because of the limited number of reactions to each stimulus. In the toe tips, the mean reaction times for each kind of stimulus showed similar variations.

The mean reaction time in the tips of the right index finger of the senile subjects, in 80 responses, was $3.86 \pm 0.04$ seconds, with a standard deviation of $0.58 \pm 0.03$ second and a coefficient of variation of $14.9 \pm 0.8$ per cent ; and in the tips of the right second toe, in 28 responses, it was $4.25 \pm 0.07$ seconds, with a standard deviation of $0.54 \pm 0.03$ second and a coefficient of variation of $12.7 \pm 1.2$ per cent (Table III). The mean reaction time in the toes was 0.39 second longer than that of the fingers, a difference which is statistically significant. The mean reaction times for each kind of stimulus in the finger were: heat, 4.16; light, 4.14 ; pistol shot, 4.06 ; pin-prick, 3.92 ; cold, 3.92 ; and bell, 3.58 seconds. The number of reaction times for each kind of stimulus was so small as to make it impossible to be certain that any of these differences was significant. The variations of the mean values for each kind of stimulus in the toes were of the same order (Table III).

The total number of satisfactory responses ob-

TABLE I

Mean values of various phases of the vascular response in the tips of the right index finger and right second toe in 17 normal resting subjects

\begin{tabular}{|c|c|c|c|c|c|c|c|c|c|c|c|c|}
\hline \multirow[b]{2}{*}{ Stimulus } & \multicolumn{10}{|c|}{ Finger tips } & \multicolumn{2}{|c|}{ Toe tips } \\
\hline & $\begin{array}{l}\text { Number } \\
\text { of reac- } \\
\text { tions to } \\
\text { stimulus }\end{array}$ & $\begin{array}{c}\text { Volume } \\
\text { of pulse } \\
\text { wave } \\
\text { before } \\
\text { stimula- } \\
\text { tion }\end{array}$ & $\begin{array}{c}\text { Volume } \\
\text { of pulse } \\
\text { wave } \\
\text { when } \\
\text { finger } \\
\text { reached } \\
\text { minimum } \\
\text { volume }\end{array}$ & $\begin{array}{c}\text { Decrease } \\
\text { in volume } \\
\text { of pulse } \\
\text { wave }\end{array}$ & $\begin{array}{c}\text { Maxi- } \\
\text { mum } \\
\text { decrease } \\
\text { in volume } \\
\text { of part }\end{array}$ & $\begin{array}{l}\text { Time } \\
\text { required } \\
\text { for part } \\
\text { to reach } \\
\text { minimum }\end{array}$ & $\begin{array}{l}\text { Time } \\
\text { required } \\
\text { for part } \\
\text { to regain } \\
\text { volume }\end{array}$ & $\begin{array}{l}\text { Time } \\
\text { required } \\
\text { for part } \\
\text { to reach } \\
\text { minimum } \\
\text { and return } \\
\text { to original } \\
\text { volume }\end{array}$ & $\begin{array}{c}\text { Reaction } \\
\text { time }\end{array}$ & $\begin{array}{l}\text { Time for } \\
\text { recovery } \\
\text { of the } \\
\text { pulse } \\
\text { wave }\end{array}$ & $\begin{array}{l}\text { Number } \\
\text { of reac- } \\
\text { tions to } \\
\text { stimulus }\end{array}$ & $\begin{array}{c}\text { Mean } \\
\text { reaction } \\
\text { time }\end{array}$ \\
\hline $\begin{array}{l}\text { Light . . . . . } \\
\text { Pin-prick . . . } \\
\text { Pistol shot . . } \\
\text { Cold . . . . . . } \\
\text { Heat . . . . . . } \\
\text { Bell . . . . . . . } \\
\text { Shock . . . . }\end{array}$ & $\begin{array}{l}24 \\
31 \\
28 \\
33 \\
24 \\
29 \\
10\end{array}$ & $\begin{array}{c}\text { c. mm. } \\
\text { per } 5 \mathrm{cc} \text {. } \\
\text { of part } \\
7.7 \\
8.5 \\
8.3 \\
7.6 \\
9.2 \\
9.0 \\
7.8\end{array}$ & $\begin{array}{c}\text { c. mm. } \\
\text { per } 5 \text { cc. } \\
\text { of part } \\
5.4 \\
5.2 \\
4.8 \\
5.1 \\
5.6 \\
6.2 \\
5.0\end{array}$ & $\begin{array}{c}\text { per cent } \\
30 \\
39 \\
42 \\
33 \\
39 \\
31 \\
36\end{array}$ & $\begin{array}{c}c . \quad m m . \\
\text { per } \delta \text { cc. } \\
\text { of part } \\
31.5 \\
35.1 \\
30.7 \\
29.8 \\
35.1 \\
29.8 \\
34.7\end{array}$ & $\begin{array}{r}\text { seconds } \\
10.6 \\
8.7 \\
10.2 \\
9.2 \\
10.2 \\
11.1 \\
12.9\end{array}$ & $\begin{array}{c}\text { seconds } \\
\\
28.2 \\
27.2 \\
24.5 \\
18.0 \\
18.4 \\
22.7 \\
33.7\end{array}$ & $\begin{array}{c}\text { seconds } \\
\\
38.1 \\
35.8 \\
36.8 \\
26.1 \\
28.0 \\
27.5 \\
43.1\end{array}$ & $\begin{array}{c}\text { seconds } \\
3.26 \\
2.95 \\
3.07 \\
3.07 \\
3.04 \\
3.33 \\
2.89\end{array}$ & $\begin{array}{c}\text { seconds } \\
34.0 \\
25.3 \\
34.9 \\
22.8 \\
28.2 \\
24.0 \\
34.5\end{array}$ & $\begin{array}{r}7 \\
19 \\
15 \\
10 \\
5 \\
7\end{array}$ & $\begin{array}{c}\text { seconds } \\
3.42 \\
3.18 \\
3.76 \\
3.56 \\
2.86 \\
3.19\end{array}$ \\
\hline Mean ..... & & 8.3 & 5.3 & 36 & 32.1 & 10.0 & 23.3 & 32.4 & 3.10 & 28.1 & & 3.38 \\
\hline
\end{tabular}

Statistical studies of the data:

Finger tips:

Reaction time: Mean $=3.12 \pm 0.02$ seconds

Standard deviation $=0.33 \pm 0.01$ second

Coefficient of variation $=10.6 \pm 0.4$ per cent

Toe tips:

Reaction time: Mean $=3.43 \pm 0.04$ seconds

Standard deviation $=0.49 \pm 0.03$ second

Coefficient of variation $=14.4 \pm 0.87$ per cent 
TABLE II

Mean values of various phases of the vascular response in the right index finger and right second toe tips of 12 resting patients with hypertension

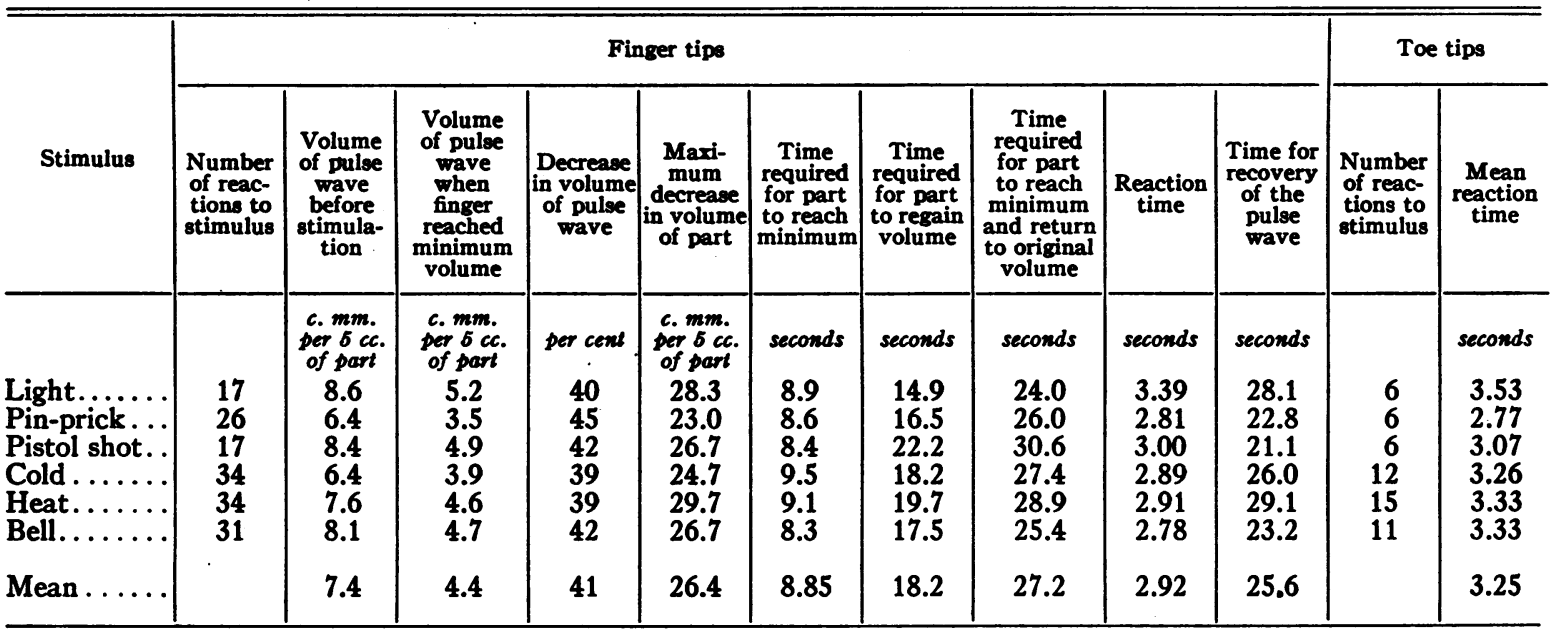

Statistical study of reaction time

Finger tips: Total number of reaction times $=159$

Mean $=2.94 \pm 0.03$ seconds

Standard deviation $=0.50 \pm 0.02$ second

Coefficient of variation $=17.0 \pm 0.7$ per cent

Toe tips: Total number of reaction times $=56$

Mean $=3.24 \pm 0.04$ seconds

Standard deviation $=0.50 \pm 0.03$ second

Coefficient of variation $=15.4 \pm 1.1$ per cent

TABLE III

Mean values of various phases of the vascular response in the right index finger and right second toe tips of 11 resting semile subjects

\begin{tabular}{|c|c|c|c|c|c|c|c|c|c|c|c|c|}
\hline \multirow[b]{2}{*}{ Stimulus } & \multicolumn{10}{|c|}{ Finger tips } & \multicolumn{2}{|c|}{ Toe tips } \\
\hline & $\begin{array}{l}\text { Number } \\
\text { of reac- } \\
\text { tions to } \\
\text { stimulus }\end{array}$ & $\begin{array}{c}\text { Volume } \\
\text { of pulse } \\
\text { wave } \\
\text { before } \\
\text { stimula- } \\
\text { tion }\end{array}$ & $\begin{array}{c}\text { Volume } \\
\text { of pulse } \\
\text { wave } \\
\text { when } \\
\text { finger } \\
\text { reached } \\
\text { minimum } \\
\text { volume }\end{array}$ & $\begin{array}{c}\text { Decrease } \\
\text { in volume } \\
\text { of pulse } \\
\text { wave }\end{array}$ & $\begin{array}{c}\text { Maxi- } \\
\text { mum } \\
\text { decrease } \\
\text { in volume } \\
\text { of part }\end{array}$ & $\begin{array}{c}\text { Time } \\
\text { required } \\
\text { for part } \\
\text { to reach } \\
\text { minimum }\end{array}$ & $\begin{array}{c}\text { Time } \\
\text { required } \\
\text { for part } \\
\text { to regain } \\
\text { volume }\end{array}$ & $\begin{array}{c}\text { Time } \\
\text { required } \\
\text { for part } \\
\text { to reach } \\
\text { minimum } \\
\text { and return } \\
\text { to original } \\
\text { volume }\end{array}$ & $\begin{array}{c}\text { Reaction } \\
\text { time }\end{array}$ & $\begin{array}{l}\text { Time for } \\
\text { recovery } \\
\text { of the } \\
\text { pulse } \\
\text { wave }\end{array}$ & $\begin{array}{l}\text { Number } \\
\text { of reac- } \\
\text { tions to } \\
\text { stimulus }\end{array}$ & $\begin{array}{l}\text { Mean } \\
\text { reaction } \\
\text { time }\end{array}$ \\
\hline $\begin{array}{l}\text { Light. . . . . . } \\
\text { Pin-prick . . } \\
\text { Pistol shot. } \\
\text { Cold . . . . . } \\
\text { Heat. . . . . . } \\
\text { Bell . . . . . . . }\end{array}$ & $\begin{array}{r}3 \\
8 \\
6 \\
28 \\
17 \\
18\end{array}$ & $\begin{array}{c}\text { c. mm. } \\
\text { per } 5 \mathrm{cc} \text {. } \\
\text { of part } \\
11.4 \\
9.4 \\
9.7 \\
9.3 \\
8.1 \\
10.5\end{array}$ & $\begin{array}{c}c . m_{m} \text {. } \\
\text { per } 5 \mathrm{cc} \text {. } \\
\text { of part } \\
9.8 \\
6.8 \\
7.4 \\
6.7 \\
6.0 \\
7.2\end{array}$ & $\begin{array}{c}\text { per cent } \\
14 \\
28 \\
24 \\
28 \\
26 \\
31\end{array}$ & $\begin{array}{c}\text { c. mm. } \\
\text { per } 5 \text { ce. } \\
\text { of part } \\
29.4 \\
12.6 \\
25.0 \\
22.2 \\
19.9 \\
30.0\end{array}$ & $\begin{array}{r}\text { seconds } \\
11.2 \\
9.1 \\
11.8 \\
13.0 \\
11.4 \\
12.5\end{array}$ & $\begin{array}{c}\text { seconds } \\
23.1 \\
15.0 \\
25.0 \\
20.1 \\
19.2 \\
33.6\end{array}$ & $\begin{array}{c}\text { seconds } \\
34.4 \\
24.5 \\
36.3 \\
32.2 \\
33.8 \\
46.2\end{array}$ & $\begin{array}{c}\text { seconds } \\
4.14 \\
3.92 \\
4.06 \\
3.72 \\
4.16 \\
3.58\end{array}$ & $\begin{array}{c}\text { seconds } \\
34.4 \\
31.8 \\
42.7 \\
29.0 \\
30.5 \\
37.8\end{array}$ & $\begin{array}{r}2 \\
1 \\
4 \\
10 \\
5 \\
6\end{array}$ & $\begin{array}{c}\text { seconds } \\
4.67 \\
4.46 \\
4.09 \\
3.85 \\
4.59 \\
4.50\end{array}$ \\
\hline Mean .... & & 9.4 & 6.9 & 27 & 22.8 & 11.9 & 22.1 & 34.7 & 3.84 & 33.4 & & 4.23 \\
\hline
\end{tabular}

Statistical study of the reaction time

Finger tips: Total number of reaction times $=\mathbf{8 0}$

Mean $=3.86 \pm 0.04$ seconds

Standard deviation $=0.58 \pm 0.03$ second

Coefficient of variation $=14.9 \pm 0.8$ per cent

Toe tips: Total number of reaction times $=28$

Mean $=4.25 \pm 0.07$ seconds

Standard deviation $=0.54 \pm 0.05$ second

Coefficient of variation $=12.7 \pm 1.2$ per cent 
tained from the senile and hypertensive patients was too small to allow for the compilation of a list showing significant differences in the times of reaction for the various stimuli. Such an attempt would be hazardous even in the normal group (178 responses), not only because of the relatively small number of responses to a single type of stimulus, but also because of individual variation in the sensitivity of subjects to stimuli applied directly to the skin.

Although there was much variation in time of reaction to successive stimuli, no correlation was established between reaction time and other factors, such as which limb of the spontaneous alpha wave was in process of formation at the time of the stimulus, frequency of application, and whether the subject was anticipating the application of a stimulus. If, as in the case of a few, subjects were asked to press a button to release a selected stimulus, their vessels became constricted when the button was pressed and no responses followed the sensory stimulus. Whenever the pulse wave was large, the response was constriction, involving, almost without exception, decrease in volume, both of the pulse wave and of the anatomical part ("alpha" wave). On the other hand, if a reaction could be detected, the initial size of the pulse wave did not seem to influence the reaction time. When the pulse was small, no clear reaction was evident, although occasionally it showed a slight decrease. In a small number of subjects, constriction of the anatomical part, as documented by a downward deflection in the "alpha" wave, was not accompanied by decrease in the size of the pulse waves. "Alpha" and pulse waves may accordingly respond independently to stimuli. Similar independence is observable in spontaneous variations (11).

In the finger tips, stimuli were effective in approximately 70 per cent of trials but in the toes, in 30 per cent only. The reason for this difference and that for the failure of so many stimuli is not known.

When reactions of the finger tip occurred at all, whether great or small, they did so after a reasonably uniform interval. But the time required to return to initial states varied widely (15 seconds to more than 3 minutes). This statement is applicable to all varieties of stimulation employed. For them all, the average recovery time in the normal group was 32 seconds, the range being 26 seconds for cold and 43 seconds for shock. The average volume of the pulse wave immediately before the application of any one of the stimuli, that is to say the initial volume, was $8.3 \mathrm{c}$. mm. On stimulation, the average minimum reached was $5.3 \mathrm{c} . \mathrm{mm}$. (a decrease of 36 per cent), the low point occurring after an average of 10 seconds. The average decrease in the volume of the part, as documented by the change in the "alpha" waves, was $32 \mathrm{c}$. $\mathrm{mm}$. The average time for the recovery of the volume ("alpha" waves) was 23 seconds, whereas the pulse waves recovered in 28 seconds (Table I, Figure 1). This difference is further evidence that the two can vary independently, though usually they do not do so. If, instead of obtaining the average reaction time in the fingers of many persons, many measurements were made of a single subject, the results turn out to be identical. In one patient, for example, the mean reaction time was $3.08 \pm 0.06$ seconds in 47 responses. This figure is not significantly different from that of the entire group. The standard deviation was $0.58 \pm 0.04$ second and the coefficient of variation, $18.9 \pm 1.4$ per cent.

The respective mean values for the various phases of the vascular response of the finger tips other than reaction times in the hypertensive and senile subjects were: the volume of the pulse waves before application of each stimulus, 7.4 and $9.4 \mathrm{c}$. $\mathrm{mm}$. per $5 \mathrm{cc}$. of part; the volume of the pulse waves when a finger reached its minimum volume, 4.4 and $6.9 \mathrm{c}$. $\mathrm{mm}$.; the percentage of decrease in volume of the pulse wave, 44 and 27 per cent; the maximum decrease in volume of the part, 26.4 and 22.8 c. mm.; time required for the part to reach a minimum volume, 8.85 and 11.9 seconds; time required for the part to regain its volume, 18.2 and 22.1 seconds; and the time for the recovery of the volume of the pulse wave, 25.6 and 33.4 seconds.

The hypertensive subjects found it very difficult to relax. Changing from a room resembling a laboratory containing much apparatus and equipment to a bedroom of ordinary appearance (10) aided in bringing on relaxation. From this bedroom, all physiological apparatus was removed. The effect of change in the room was similar in

4 Changes in volume are given for 5 c. $\mathrm{mm}$. of anatomical part. 
senile patients, but practically no change was noticeable in the normal group which was recruited in great part from persons familiar with the procedures in laboratories.

Stimuli, such as bell and light, which could be used without the presence of an observer in the patient's room, were more frequently successful in eliciting responses than those which were applied by an observer in the room. With such a one present, the patients became tense and their vessels constricted at first, though relaxation took place after a short interval. Often it was not complete until the observer left the room. Senile subjects were less sensitive to this situation than hypertensive patients. When a stimulus was especially unpleasant to a hypertensive patient, he remained apprehensive and his blood vessels remained constricted for a long period of time, often for the duration of that particular observation. Such phenomena were less often encountered in senile subjects than in hypertensive patients. In fact, patients with hypertension were conspicuous in being unable to relax and in their tendency to be psychologically disturbed. The statements of patients on the tenseness of their sensations and their appearance of being ill at ease ran parallel with the occurrence of persistent vasoconstriction. If a reaction occurred, even if the vessels were constricted, the reaction time was essentially the same as when the vessels were dilated.

"Alpha" deflections documenting constriction of a part in response to stimuli differed from the alpha waves during spontaneous variations (3) in at least five ways: (1) After stimulation, vasoconstriction occurred more abruptly than during spontaneous variation. (2) After repeated stimulations at close intervals, the resulting downward deflections were more persistent than in the case of a series of spontaneous variations. (3) After stimulation, upward deflections did not occur. (4) In random samples of records of spontaneous variations taken for brief periods ( 3 seconds), downward deflections were rare. After stimulation, they occurred frequently in the fingers (65 to 70 per cent) and less frequently in the toes (30 per cent). (5) During periods of spontaneous variation, simultaneous, exactly synchronous downward deflections in both (right and left) fingers and toes were rare, though they were often concordant. After stimulation, abrupt simultaneous downward deflections were the rule.

When there was reaction to stimulation, it resulted always in reduction in volume of the fingers and toes, never in dilatation. Nor was there ever increase in the size of the pulse waves. Reaction to heat did not differ from that of other stimuli. The reaction time was almost invariably the same in right and left index fingers and in right and left second toe tips, as has just been implied.

Two patients with hypertension were operated on. ${ }^{3}$ Three weeks after operation, the volumes of the pulse waves in the toes in both were larger and those in the fingers smaller than before operation. The vessels of the toes did not react to stimuli while those of the fingers reacted poorly.

\section{DISCUSSION}

In any study of the reactivity of the blood vessels, clearly an analysis of the pathway stimuli follow is important. In intact human beings, direct measurement of the time consumed in traversing each of the component parts of that pathway is impossible. There are involved, the time taken by the reception of the stimulus, the passage of the resulting impulse through the central nervous system, the effector pathway, and the local complex mechanisms which result in contraction of the blood vessels. The passage of the impulse from the point of reception and through the central nervous system occurs rapidly. The post-ganglionic fibers of the sympathetic nervous system, the ones most probably concerned in the transmission to the blood vessels, conduct impulses at varying rates in the order of $1 / 2$ to 1 meter per second. In order to attempt an explanation of the delay in reaction time in the case of the toes, different assumptions may be entertained. If it can be assumed that the local mechanisms involved in the contraction of the blood vessels in the fingers and toes are alike, the added distance impulses must travel to the toes accounts for the delay of the order of 0.30 second. It is possible on the other hand that the major part of the delay is not consumed in the transmission of impulses over paths of different lengths but is due to differences in local mechanisms in

\footnotetext{
5 The operation consisted of section of the sympathetic nerves from the 9th dorsal to the 1st lumbar, together with excision of the celiac and aortic-renal ganglia on both sides.
} 
fingers and toes. It seems likely now that the difference in length of pathways is sufficient to account for the delay to the toes. The notion is not yet to be excluded however that local differences, as for example a mere matter of the number of units of nerves or receptors, may be concerned in the result. There is a third possibility; delay may result from the pathway within the spinal cord over which an impulse must pass when received from the upper part of the body, before it reaches that level of the cord from which it emerges to proceed to the lower extremity. There is a final consideration. There is often detected a difference in reaction time, in multiples as great as 2 . These differences are now not understood. They do not depend on any factors which it has been possible to identify. That variations from subject to subject or from time to time in the same subject are dependent on variations in the conduction rates of the impulses through nerves is unlikely; it is more likely due to variations in the blood vessels. But on such problems, no definite data have been established.

Since the method now employed measures the constriction of the entire finger or toe tip, which of the many types of blood vessels reacted first or accounted for most of the constriction cannot be known. The fact that in some subjects the reaction resulted in a reduction in volume without concomitant reduction in the size of the pulse wave tends to indicate that vessels other than arteries and arterioles also react to the stimuli. The reaction times found in these studies were never as great as those reported by Fano (7) who found values as high as 7 seconds.

The range of variation in the time occupied in reacting to a stimulus was moderately wide, but not nearly as wide as that required to bring about maximum constriction of a part. Many factors, most of them unknown and beyond control, play a part in influencing both the time and the degree of the total response. The importance of the immediate environment has already been emphasized. And it has already been remarked that subjects vary from moment to moment. When all the causes of variation are taken into account, the fact remains that there is great regularity in the physiological control of blood vessels.

The question has been weighed whether impulses which traverse the brain have reaction times different from those which may pass only through the spinal cord. The mean reaction times in the fingers of normal subjects for light, bell, and pistol shot were 3.26, 3.33, and 3.07 seconds. Those for shock, pin-prick, cold, and heat were 2.89, 2.95, 3.07, and 3.04 seconds (Table I). At first glance, it appears that a reflex passing through the brain experiences a delay. The fact that both pistol shot and cold consume the same time is not easily reconciled with this view.

The vascular responses to the stimuli were widely distributed, having occurred almost simultaneously in fingers and toes on both sides. There was, in addition, definite slowing of the heart rate (Figure 2).

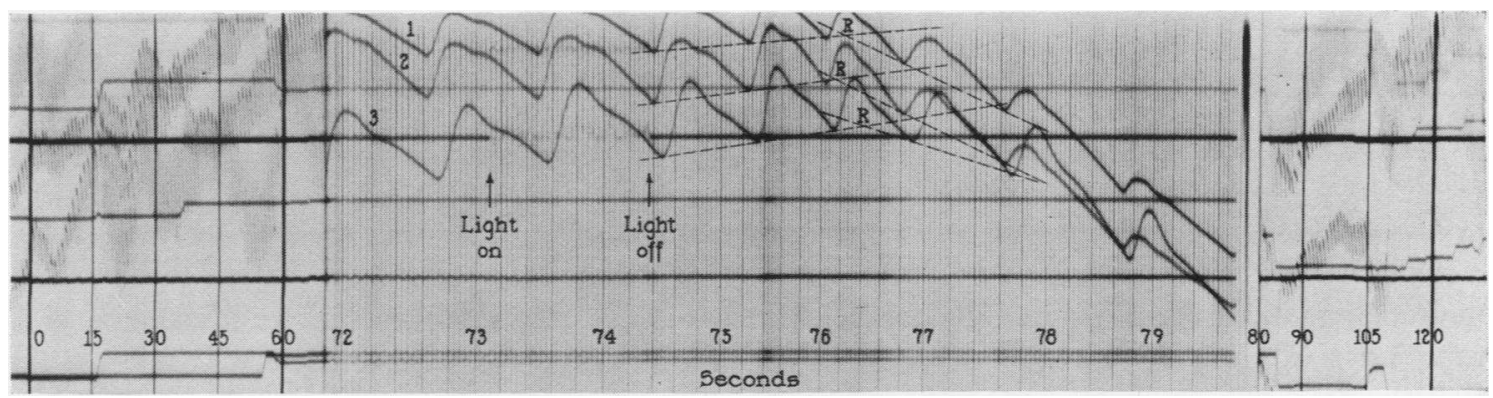

Fig. 2. A Representative Original Record of the Tips of the Right, 1, and Left, 2, Index Finger and the Right, 3, Second Toe

These are simultaneous records. From about the 72 nd to 80 th seconds, the camera speed was approximately $6 \mathrm{~cm}$. per second while otherwise the speed was about $8 \mathrm{~cm}$. per minute. $R$ indicates the point at which vasoconstriction occurred. This point was found at the intersection of a line which joined the foot points of the last 4 pulse waves just before the volume of the part changed and another one through the first few pulse waves just after vasostriction began. The time of reaction was measured from the point of the application of the stimulus to the point $R$. Bradycardia is evident during the period of vasoconstriction. 


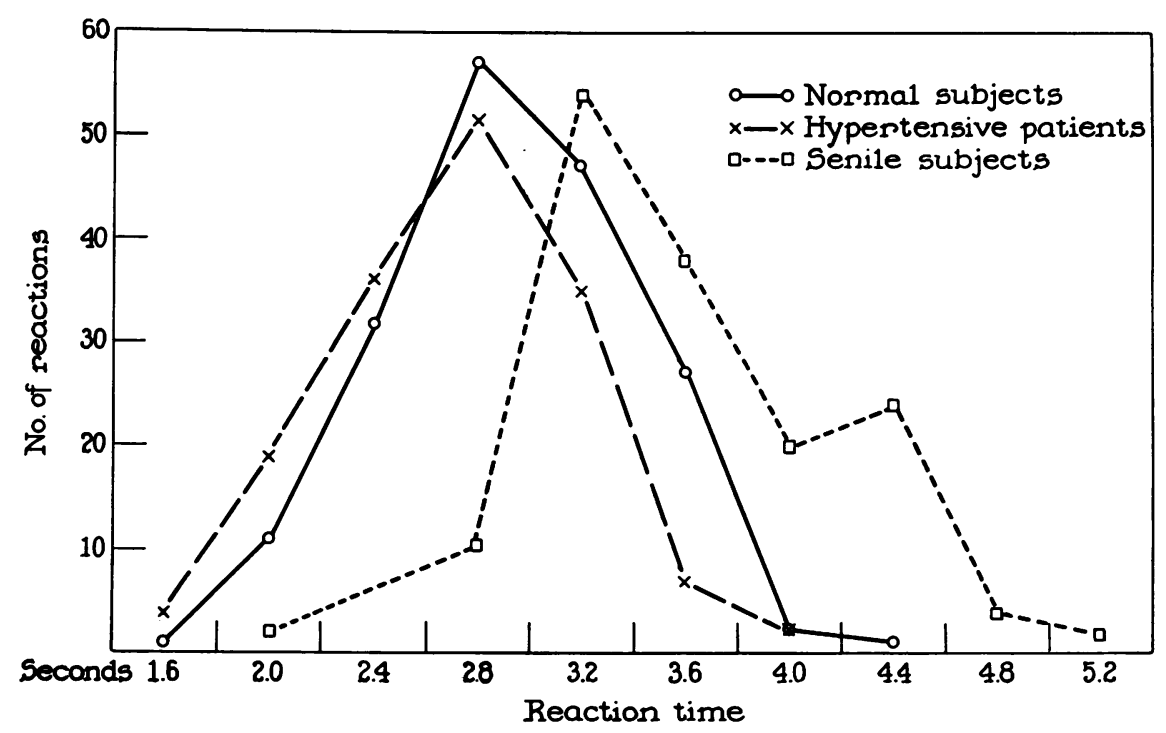

Fig. 3. Distribution Curves Giving the Reaction Times of Normal, Hypertensive, and Senile Individuals

These curves overlap. The curve of the hypertensive patients is farther to the left than that of the normal persons; that of the senile subjects, relatively farther to the right. This curve (senile) has a wider distribution than the other two.

The degree of vasoconstriction, suddenness of constriction, duration of constriction, time required for the constriction to reach its limit, and the time required for recovery were not materially different in the case of any of the stimuli used (Table I). There was no method available according to which normal subjects could be grouped on the basis of any aspect of their responses.

It was noticed that some individuals were made much more apprehensive by certain stimuli than by others. In some subjects, the electric shock, the pistol shot, or even heat or cold were so distressing as to prevent them from relaxing normally. The electric shock produced apprehension most often. After the first observation, those stimuli which produced psychic discomfort were recognized. On the next observation, the subject was informed at the beginning of the study that the offending stimulus would not be employed. Invariably it was found that relaxation then occurred more quickly and completely. During some observations, a subject would relax and would respond to stimuli which were not disagreeable but would, once one was found to be so from a psychological point of view, react so that his blood vessels contracted but would not recover within a reasonable period of time. The vessels remained tightly constricted, the patient became afraid, and no further reactions of the blood vessels were detected, regardless of the stimulus applied. It was found that the stimuli, the room (10), the entrance of a strange observer, and many other factors which are usually regarded as innocuous would often disturb the patient sufficiently to prevent satisfactory relaxation. It is impossible in such a study, or in all probability in any other type of physiological study on the vascular system in conscious human beings, to overemphasize the importance of psychological factors. Emotional or ideational stimuli, such as result from conversations involving sex, business, or matters of personal concern, elicited vascular reactions similar to those described in the case of mechanical stimuli.

The measurements demonstrate that the times of reaction in the fingers of senile subjects and of hypertensive patients are reasonably close to those of normal persons (3.12), but that those of the senile ones are longer (3.86), and those of the hypertensive ones, shorter (2.94) (Figure 3). The difference, 0.18 second, between normal persons and patients with hypertension is statistically significant. It should not be over-emphasized, nevertheless, because these measurements are not 
accurate beyond \pm 0.05 second. Aside from the differences in reaction time, other aspects of the nature of the vascular response are distinctive. The slope of the curve is more precipitous, the state of maximum constriction is attained more quickly, the reaction takes place to a greater degree, and is over more quickly, than in the normal people. If, instead of a stimulus which is innocuous, psychologically, and which has no psychological persistence, stimuli occurred or were applied which were more painful or more farreaching in influence, the continuance of constriction would exhibit far greater duration. This observation suggests that, in hypertensive patients, the impact of usual occurrences, not ordinarily regarded as harmful, in daily life result in effects upon their vascular systems of a degree and a duration beyond that experienced by normal persons. Unfortunately, it has been impossible to measure changes in the blood pressure. No satisfactory apparatus free from the danger of occasioning psychological stress that would serve the current purpose is now available.

In the senile subjects, clearly the reaction times of the fingers and toes were much longer than in normal or hypertensive persons. The reaction takes place, furthermore, not only more slowly but the entire response is slow to reach its maximum, slow to recover, the degree of the response is less, and the entire response has the appearance of less vigor. The distribution curves of the times of reaction of the finger tips of the three groups of subjects illustrate these differences. The means in these three groups are distinct. There is a considerable amount, nevertheless, of overlapping of these values. The shapes of the distribution curves are such that the hypertensive curve which is to the left exhibits a fair sized area of overlapping while that of the senile group to the right, is much wider, and so comes to coincide less with the normal curve. As quantities, though significant, these differences are small; as qualities to be perceived clinically, they are very distinct.

The reactions in the toes of the hypertensive patients and senile subjects took place 0.30 and 0.39 second later, respectively, than in the fingers. These differences indicate no difference statistically among the three groups when compared with the value of 0.31 in normal individuals.
By good fortune, it was possible to learn more intimately the path which these impulses traversed. The observation was made possible by the 2 patients with hypertension who were operated upon. Their sympathetic nerves, after they were cut, naturally failed to convey impulses and so could not serve as the efferent limits of reflex arcs set in motion by sensory stimuli. Expected responses, therefore, did not occur.

\section{SUM MARY}

The mean reaction times in the tips of the fingers in normal (3.12) and in senile persons (3.86) differ from those in hypertensive patients (2.94), being most rapid in the hypertensive and slowest in the senile persons. In the tips of the toes, the general arrangement is the same, being fastest in hypertensive subjects (3.24) and slowest in the senile (4.25). In the toes, the delay (beyond the fingers) is of the same order of magnitude in each of the three groups. This can be accounted for on the basis of the time required for the efferent impulses to traverse the additional length of post-ganglionic sympathetic fibers in order to reach the toes. The stimuli used were diffuse light, heat, cold, pin-prick, sudden loud noise (pistol-shot), and electric shock. There was no significant difference in the normal group among the stimuli used in the reaction time or in any part of the total vascular response, such as time for the vasoconstriction to reach a maximum, degree of change in the volume of the pulse wave, time for recovery, and suddenness of response. It was not possible to group persons on the basis of their reactions to the stimuli.

The stimuli, light and bell, which were applied while subjects were alone were more satisfactory than those which, when applied, necessitated the presence of an observer. Psychological factors, often apparently very mild, influenced the responses significantly, which indicated the extreme importance of recognizing them during peripheral vascular studies on conscious human beings.

No correlation was found, provided a reaction to the stimulus occurred, between the reaction time and the state of the vascular bed of the part. The reaction time was essentially not affected by the fact that the vascular bed was already in a contracted or dilated state or was constricting or 
dilating when the stimulus was applied. This was not the case concerning the degree of change in volume of the vascular bed during the response. The more constricted the vascular bed at the time of stimulation, the less change in volume.

In general, the data strongly suggest that reaction time was more rapid, the vascular response occurred more suddenly and to a greater degree and was over more rapidly, in hypertensive than in normal persons.

In the senile subjects, the reaction time was less rapid than normal and the vascular response occurred more slowly, to a less degree, and the recovery was much slower.

The reason for these differences is unknown. These differences can be owing to changes in the vessels themselves or in factors outside the vessels such as the nervous system or in chemical states which influence the vessels.

\section{BIBLIOGRAPHY}

1. Burton, A. C., The range and variability of the blood flow in the human fingers and the vasomotor regulation of body temperature. Am. J. Physiol., 1939, $127,437$.

2. Hertzman, A. B., and Dillon, J. B., Selective vascular reaction patterns in the nasal septum and skin of the extremities and head. Am. J. Physiol., 1939, $127,671$.
3. Burch, G. E., Cohn, A. E., and Neumann, C., A study by quantitative methods of the spontaneous variations in volume of the finger tip, toe tip, and postero-superior portion of the pinna of resting normal white adults. Am. J. Physiol., 1942, 136, 433.

4. Evans, C. L., The physiology of plain muscle. Physiol. Rev., 1926, 6, 358.

5. Lapicque, L., and Lapicque, M., Chronaxie des vaisseaux et des cellules pigmentaires chez la grenouille. Soc. Biol., Paris, 1924, 91, 267.

6. Fredericq, H., Chronaxie. Physiol. Rev., 1928, 8, 501.

7. Luciani, L., Physiologie des Menchen. Fischer, Jena, 1905, vol. 1, pp. 290-291.

8. Hines, E. A., and Brown, G. E., A standard test for measuring the variability of blood pressure: Its significance as an index of the prehypertensive state. Ann. Int. Med., 1933, 7, 209.

9. Turner, R. H., Studies in the physiology of blood vessels in man. Apparatus and Methods. I. A sensitive plethysmograph for a portion of the finger. J. Clin. Invest., 1937, 16, 777.

10. Neumann, C., Cohn, A. E., and Burch, G. E., A study of the influence of the character of an examining room on the peripheral blood vessels of normal, hypertensive, and senile subjects. J. Clin. Invest., 1942, 21, 651.

11. Neumann, C., Cohn, A. E., and Burch, G. E., A study of the relationship between pulse and alpha waves of the tips of the fingers and toes of five adults. Am. J. Physiol., 1942, 136, 448. 